\title{
Combined Colorimetric and Gravimetric CMUT Sensor for Detection of Phenylacetone
}

Mølgaard, Mathias Johannes Grøndahl; Laustsen, Milan; Thygesen, Ida Lysgaard; Jakobsen, Mogens Havsteen; Andresen, Thomas Lars; Thomsen, Erik Vilain

Published in:

2017 IEEE International Ultrasonics Symposium (IUS)

Link to article, DOI:

10.1109/ULTSYM.2017.8091676

Publication date:

2017

Document Version

Peer reviewed version

Link back to DTU Orbit

Citation (APA):

Mølgaard, M. J. G., Laustsen, M., Thygesen, I. L., Jakobsen, M. H., Andresen, T. L., \& Thomsen, E. V. (2017). Combined Colorimetric and Gravimetric CMUT Sensor for Detection of Phenylacetone. In 2017 IEEE International Ultrasonics Symposium (IUS) IEEE. https://doi.org/10.1109/ULTSYM.2017.8091676

\section{General rights}

Copyright and moral rights for the publications made accessible in the public portal are retained by the authors and/or other copyright owners and it is a condition of accessing publications that users recognise and abide by the legal requirements associated with these rights.

- Users may download and print one copy of any publication from the public portal for the purpose of private study or research.

- You may not further distribute the material or use it for any profit-making activity or commercial gain

- You may freely distribute the URL identifying the publication in the public portal 


\title{
Combined Colorimetric and Gravimetric CMUT Sensor for Detection of Phenylacetone
}

\author{
Mathias J. G. Mølgaard*, Milan Laustsen*, Ida L. Thygesen*, Mogens H. Jakobsen*, Thomas L. Andresen*, \\ and Erik V. Thomsen* \\ *Department of Micro and Nanotechnology, Technical University of Denmark, DK-2800 Kgs. Lyngby, Denmark
}

\begin{abstract}
The detection of phenylacetone is of interest as it is a common precursor for the synthesis of (meth)amphetamine. Resonant gravimetric sensors can be used to detect the mass and hereby the concentration of a gas while colorimetric arrays typically have an exceptional selectivity to the target analyte if the right colorimetric dyes are chosen. We present a sensor system consisting of a Capacitive Micromachined Ultrasonic Transducer (CMUT) and a colorimetric array for detection of phenylacetone. The CMUT is used as a resonant gravimetric gas sensor where the resonance frequency shift due to mass loading of the plate. A single Local Oxidation of Silicon (LOCOS) step was used to define the cavities which were sealed with a $\mathrm{Si}_{3} \mathrm{~N}_{4}$ plate with a thickness of $100 \mathrm{~nm}$, resulting in a resonance frequency of $38.8 \mathrm{MHz}$ and a theoretical mass sensitivity of $28.3 \frac{\mathrm{zg}}{\mathrm{Hz} \cdot \mu \mathrm{m}^{2}}$. The CMUTs were functionalized with the same dyes used to fabricate colorimetric arrays. While both the CMUTs and the colorimetric arrays showed selectivity to phenylacetone, the best selectivity was achieved by the colorimetric array. Furthermore, the mass of the phenylacetone was found as a function of time. Thus, the combination of the colorimetric array and the CMUT results in a good selectivity and a quantitative value for the mass.
\end{abstract}

\section{INTRODUCTION}

Detection of illegal drug and explosive precursors is of interest for government agencies in order to prevent or stop this type of criminal activity. Amphetamine and methamphetamine are recreational drugs and illegal to possess in many countries as they are controlled substances. Multiple synthesization routes exists where a common one is the reductive amination of the illegal precursor molecule phenylacetone/BMK [1]. Therefore, it is desirable to be able to detect BMK, especially in the gas phase.

CMUTs have previously been used for sensing applications: In 2007 Park et al. demonstrated the use of CMUTs as sensors by detecting water, isopropanol, acetone, and methanol [2]. Detection of chemical weapons is another possible use case for the CMUT sensor as it can detect very small concentrations. Dimethyl methylphosphonate (DMMP) which is a common simulant for sarin has been measured in the gas phase with a CMUT sensor with a high volume sensitivity and low limit of detection while obtaining a good selectivity towards dodecane and 1-octanol [3] [4]. CMUTs have also been used as biosensors, specifically as an immunosensor where the antigen antibody pair interacts in a highly selective reaction causing the resonance frequency to decrease [5]. Finally, CMUTs have also been used for environmental monitoring where the concentration of $\mathrm{CO}_{2}$ has been measured [6] [7].
A functional layer is needed in order to make the gravimetric sensors selective towards a specific analyte. Functionalization is typically done by applying a thin polymer coating on top of the vibrating part. Due to the 'closed' and planar surface of the CMUT device several methods can be employed including: spin coating, drop coating, dip coating, and spray coating. Despite of these layers, obtaining a very high selectivity still remains as a challenge for gravimetric sensors and therefore also CMUTs. One method of improving selectivity between multiple analytes in a gas has been to employ several CMUTs each coated with a different functionalization layer [8]. A single chip with several CMUT elements can easily be fabricated, thus minimizing the footprint and complexity.

In this paper we combine a CMUT sensor with a colorimetric array to detect BMK. By doing this we benefit from the high selectivity offered by the colorimetric array and the quantitative output of the CMUT which can be related to the concentration of the analyte. Furthermore, having two independent sensor types combined provides the total sensor system with redundancy. We present the fabrication and characterization of the CMUT and colorimetric array. The intensity as a function of time and resonance frequency shift as a function of time for the colorimetric array and CMUT respectively shows that the dyes provide both sensor types with a selectivity towards BMK.

\section{DEVICES}

In this section the fabrication and characterization of the CMUTs and colorimetric chips are described.

\section{A. CMUT}

1) Fabrication: The CMUT cells were fabricated using a single local oxidation of silicon (LOCOS) step and fusion wafer bonding. CMUTs have previously been fabricated by fusion bonding $\mathrm{SiO}_{2}$ and $\mathrm{Si}_{3} \mathrm{~N}_{4}$ surfaces but the cavities where in these cases made with a RIE process [9] [10].

The complete process flow can be seen in Figure 1. In step (1) $\mathrm{a} \mathrm{SiO}_{2}$ layer was grown on a low electrical resistivity $\mathrm{Si}$ wafer $(<0.025 \Omega \mathrm{cm},<100>)$. This $\mathrm{SiO}_{2}$ layer separates the $\mathrm{Si}_{3} \mathrm{~N}_{4}$ layer from the $\mathrm{Si}$ surface which otherwise could have defects introduced due to a tensile stress of $\sim 1.3 \mathrm{GPa}$ in the $\mathrm{Si}_{3} \mathrm{~N}_{4}$. Further, the $\mathrm{Si}_{3} \mathrm{~N}_{4}$ layer was patterned using UV lithography and a $\mathrm{H}_{3} \mathrm{PO}_{4}$ etch. Subsequently, LOCOS was performed (step (2)) using the patterned $\mathrm{Si}_{3} \mathrm{~N}_{4}$ as the 
(1)

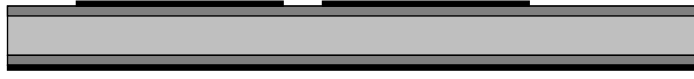

(2)

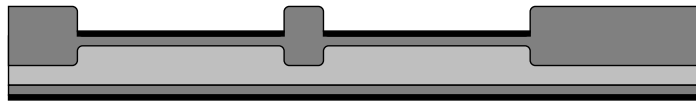

(3)



(4)

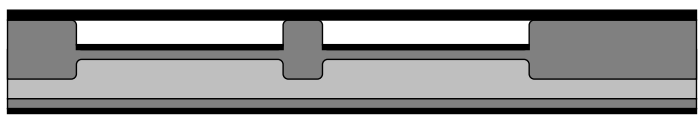

(5)

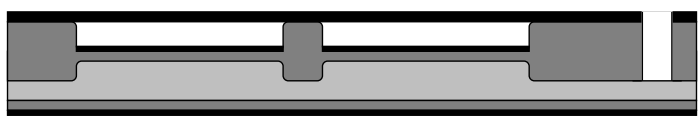

(6)

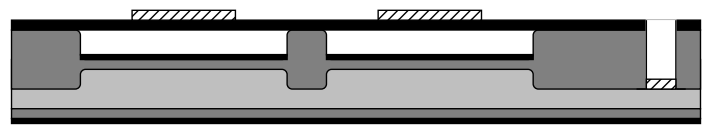

$\mathrm{Si}$ $\mathrm{SiO}_{2}$

$\mathrm{Si}_{3} \mathrm{~N}_{4}$ $\forall \mathrm{Al}$

Fig. 1. Process flow for the CMUT.

oxidation mask. The cavities were sealed under vacuum in a wafer bonding machine (step (3)) by bonding the cavity wafer with a $\mathrm{Si}$ wafer with a layer of $\mathrm{Si}_{3} \mathrm{~N}_{4}$. In step (4) the top $\mathrm{Si}_{3} \mathrm{~N}_{4}$ layer was etched by a dry etch and the $\mathrm{Si}$ by a $\mathrm{KOH}$ etch. $\mathrm{KOH}$ was chosen due to the high etch selectivity between $\mathrm{Si}$ and $\mathrm{Si}_{3} \mathrm{~N}_{4}$. Hence, the $\mathrm{Si}_{3} \mathrm{~N}_{4}$ plate and the $\mathrm{Si}_{3} \mathrm{~N}_{4}$ layer on the backside of the cavity wafer acted as etch stop layers. Bottom electrode openings were etched in step (5) with a dry etch and finally $\mathrm{Al}$ was deposited and patterned in step (6) using a $\mathrm{H}_{3} \mathrm{PO}_{4}: \mathrm{H}_{2} \mathrm{O}$ etch at room temperature.

2) Dimensions and characterization: A single element consists of 1024 cells connected in parallel. This parallelism lowers the impedance and increases the signal to noise ratio. The dimensions and properties of the elements can be seen in Table I. The value of the tensile stress of the $\mathrm{Si}_{3} \mathrm{~N}_{4}$ is found by measuring the curvature of a double side polished wafer with a layer of $\mathrm{Si}_{3} \mathrm{~N}_{4}$ of known thickness on one side and then applying Stoney's equation. The tensile stress increases both the resonance frequency and pull-in voltage compared with a similar plate with no stress [11].

The resonance frequency and pull-in voltage is found from impedance spectra. Three such spectra can be seen in Figure 2 where also the well-known spring softening effect is observed.

3) Sensitivity: Mass sensitivity is one of the key figures of merit of a gravimetric sensor. It can be calculated theoretically by approximating the CMUT as a 1-D linear harmonic oscillator and assuming that the mass added to the plate is much smaller than the mass of the plate. The distributed mass sensitivity can then be expressed as:
TABLE I

PROPERTIES OF THE FABRICATED CMUTS.

\begin{tabular}{l|c}
\hline \hline Parameter & Value \\
\hline Radius, $a$ & $5 \mu \mathrm{m}$ \\
Plate thickness, $t$ & $100 \mathrm{~nm}$ \\
Metal thickness & $100 \mathrm{~nm}$ \\
Gap height & $255 \mathrm{~nm}$ \\
$\mathrm{LOCOS} \mathrm{Si}_{3} \mathrm{~N}_{4}$ thickness & $50 \mathrm{~nm}$ \\
$\mathrm{Si}_{3} \mathrm{~N}_{4}$ tensile stress & $1.3 \mathrm{GPa}$ \\
Number of cells & 1024 \\
Resonance frequency, $f_{0}\left(V_{\mathrm{DC}}=\frac{2}{3} V_{\mathrm{PI}}\right)$ & $38.8 \mathrm{MHz}$ \\
Pull-in voltage & $150 \mathrm{~V}$ \\
\hline \hline
\end{tabular}

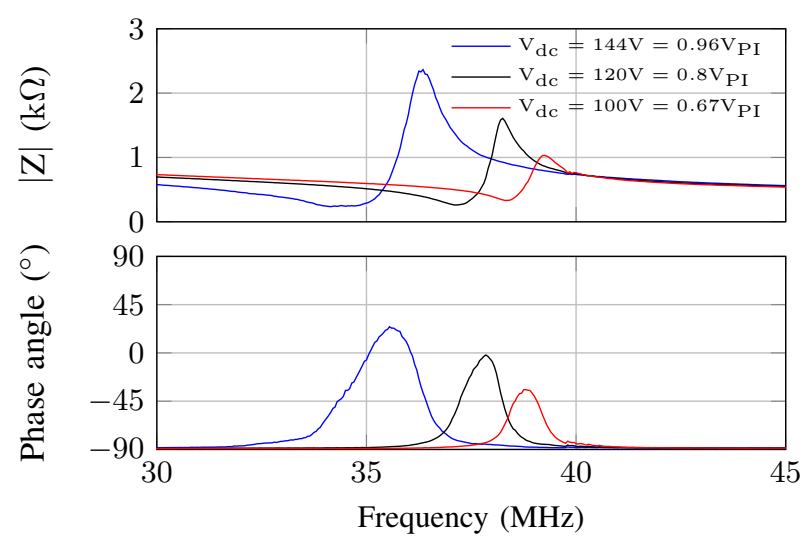

Fig. 2. Impedance spectra of a CMUT device at three different bias voltages.

$$
S=\frac{\partial f_{0}}{\partial m}=-\frac{1}{2} \frac{f_{0}}{m_{\text {plate }}},
$$

where $f_{0}$ is the resonance frequency and $m_{\text {plate }}$ is the mass of the plate. The sensitivity is increased by having a plate with a high resonance frequency and a low mass. The sensitivity is in this paper sought maximized by having a plate thickness of $100 \mathrm{~nm}$, decreasing the mass of the plate, while still maintaining a resonance frequency of $38.8 \mathrm{MHz}$.

The theoretical sensitivity, $S_{\text {theoretical }}$, has been calculated using Equation 1 and can be seen in Table II. In addition, a measured sensitivity is given in the same table. The measurements are performed by finding the resonance frequency from impedance spectra and subsequently depositing a thin layer of $\mathrm{Au}$ on the CMUT element. By measuring the step height of the deposited $\mathrm{Au}$ the added mass on the plate is calculated. Repeating the impedance measurement and deposition step, values of the resonance frequency as a function of added mass is found. The sensitivity was directly found from the slope of such a graph. Table II gives the inverse of this slope value together with the theoretical value calculated by means of Equation 1. The ratio $S_{\text {measured }} / S_{\text {theoretical }}=1.86$ shows that the measured sensitivity is worse than the predicted theoretical value. This can be due to an overestimation of the added Au mass or a violation of the assumption for Equation 1 stating that $m_{\text {plate }} \gg>m_{\mathrm{Au}}$ since $m_{\text {plate }} / m_{\mathrm{Au}} \sim 3$. In order to decrease the discrepancy between the theoretical and measured value either a thinner Au layer or a layer of lower density 
TABLE II

TABLE OF THEORETICAL AND MEASURED SENSITIVITIES AND LODS OF THE CMUT DEVICE.

\begin{tabular}{l|c}
\hline \hline Parameter & Value \\
\hline$S_{\text {theoretical }}$ & $2.2 \frac{\mathrm{ag}}{\mathrm{Hz}}$ \\
$S_{\text {measured }}$ & $4.1 \frac{\mathrm{ag}}{\mathrm{Hz}}$ \\
$S_{\text {theoretical }} / A$ & $28.3 \frac{\mathrm{zg}}{\mathrm{Hz} \cdot \mu \mathrm{m}^{2}}$ \\
$S_{\text {measured }} / A$ & $51.8 \frac{\mathrm{zg}}{\mathrm{Hz} \cdot \mu \mathrm{m}^{2}}$ \\
$\mathrm{LOD}(1 \sigma)$ & $2.0 \mathrm{ag}$ \\
$\mathrm{LOD} / \mathrm{A}(1 \sigma)$ & $25.8 \frac{\mathrm{zg}}{\mu \mathrm{m}^{2}}$ \\
\hline \hline
\end{tabular}

should be used. In Table II the sensitivity normalized with the area of the CMUT cell is also given in order to make comparisons with other sensors easier.

4) Limit of detection: The mass limit of detection (LOD) is a measure of the minimum change in mass a sensor can detect due to frequency noise. The LOD can be estimated by the following relation [12]:

$$
\operatorname{LOD}(\tau)=2 m_{\text {plate }} \sigma(\tau),
$$

where $m_{\text {plate }}$ is the mass of the plate and $\sigma(\tau)$ is the Allan deviation. The Overlapping Allan Deviation has been measured and the minimum limit of detection calculated, see Table II.

\section{B. Colorimetric chip}

The colorimetric arrays consist of two columns of dye spots where each column comprises several spots, see Figure 3 a). The spots in the left column, called coating A, is Reichardt's dye and the dye in the right column, called coating $\mathrm{B}$, is Bengal rose $\mathrm{B}$. Coating $\mathrm{A}$ is expected to react with BMK, that is change color, while coating B is not expected to react. The spots are made by dispensing several drops of dye in a liquid solution on a white polypropylene substrate. The dispensing and spot pattern are controlled by a computer and an automatic dispensing machine (GESIM, Nano-Plotter) using a piezoelectric actuated needle. The same setup is also used to coat the CMUT surfaces with dye. The two dyes used for the colorimetric arrays are used as functionalization layers on the CMUTs. The thickness of the dye on the CMUT was chosen so the resonance frequency did not significantly change compared with the uncoated state.

\section{EXPERIMENTAL SETUP}

The experimental setup is constructed so that the CMUT frequency shift and colorimetric color change can be measured at the same time. The CMUTs and the colorimetric chip are placed in a small $\left(\sim 72 \mathrm{~cm}^{3}\right)$ chamber, see Figure 3 b). Through an inlet hole in the chamber, analytes can be introduced. A microscope takes an image of the colorimetric chip every $30 \mathrm{~s}$ through the transparent top of the chamber. An example of such an image can be seen in Figure 3 a). The

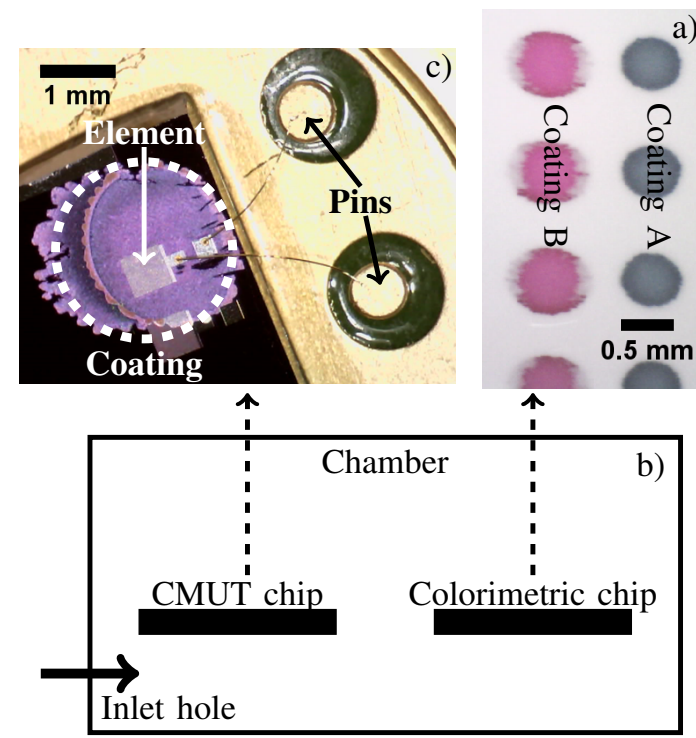

Fig. 3. a) optical microscope image of the colorimetric chip showing two columns of dye. b) schematic of the experimental setup. c) optical microscope image of the CMUT chip wirebonded to two pins. A single element is seen, coated with a dye.

CMUT is glued to a TO-8 head and Au wirebonds connect the top and bottom electrodes to two pins, see Figure $3 \mathrm{c}$ ). The coated CMUT element is also visible in this figure. Further, the two pins are connected to a bias tee which supplies the CMUT with a bias DC voltage (Keithley 2410) and an AC voltage from a lock-in amplifier with a built-in phase locked loop (Zurich Instruments, HF2LI PLL). The PLL ensures that the CMUT is driven at resonance while the resonance frequency shifts are saved to a computer. The resonance frequency can be measured for two CMUT elements simultaneously.

\section{RESULTS AND DISCUSSION}

Figure 4 shows the intensity as a function of time for the two dyes. The intensity is calculated by taking the mean of the RGB channel intensities inside the dye spots for difference maps. In Figure 4 coating A shows an increase in intensity after BMK is injected at $t=4 \mathrm{~min}$. At about $t=15 \mathrm{~min}$ the intensity is constant and it is assumed that all the dye has reacted with the BMK. The opposite is true for coating $\mathrm{B}$, here the intensity is more or less constant for the entire duration indicating no change in color. No color change is observed, for either coating, when acetone or water is injected. Acetone is chosen as an analyte since the molecular structure is the same as BMK expect for an aromatic ring and water is chosen since water vapour is almost always present in the atmosphere. Figure 4 demonstrates that coating $\mathrm{A}$ has an affinity towards BMK. Furthermore, coating A shows selectivity between BMK, acetone and water, since no color change is observed for the two latter analytes.

Figure 5 shows the frequency shift for three CMUTs: one with coating $\mathrm{A}$, one with coating $\mathrm{B}$ and one without any coating. The added mass on the right axis is calculated using 


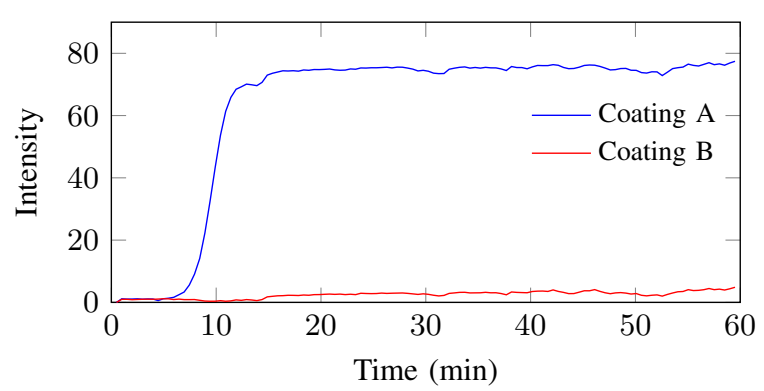

Fig. 4. Mean intensity of the red, green and blue channels as a function of time. BMK is injected into the chamber at $t \approx 4 \mathrm{~min}$. Background intensity has been subtracted.

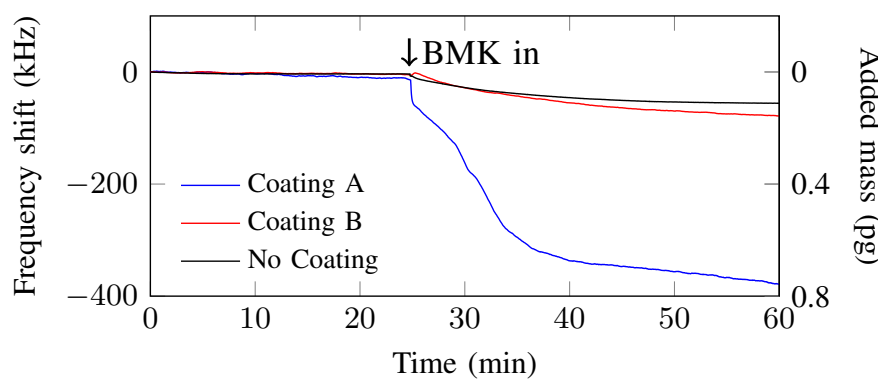

Fig. 5. Frequency shift as a function of time with BMK as the analyte.

Equation 1 and the measured frequency shift. At the time indicated in Figure 5, BMK is injected into the chamber. Consequently, the resonance frequency decreases due to the added mass of the evaporated analyte. The bigger frequency shift for the CMUT with coating A compared with coating B and the CMUT with no coating, shows, again, that coating A has an affinity towards BMK. Thus, coating A both gives the biggest change in intensity (due to a color change) (Figure 4) compared with coating B and a larger frequency shift than coating B with BMK as an analyte. Water was also used as an analyte in order to test the selectivity of the coatings and whether the difference observed, for BMK, is due to the coatings and not due to differences of the CMUTs themselves. With water as an analyte coating A had the smallest frequency shift. Coating $\mathrm{A}$ is therefore exhibits selectivity both when used as a coating on the CMUTs and when used as a dye in the colorimetric chip.

\section{CONCLUSION}

A sensor system consisting of a CMUT and a colorimetric array was presented. The CMUT was fabricated using a single LOCOS step and wafer bonding to a $\mathrm{Si}_{3} \mathrm{~N}_{4}$ layer on a double side polished $\mathrm{Si}$ wafer, thus eliminating the need for expensive SOI wafers. Furthermore, the CMUT had a calculated sensitivity of $28.3 \frac{\mathrm{zg}}{\mathrm{Hz} \cdot \mu \mathrm{m}^{2}}$ and a $\operatorname{LOD}(1 \sigma)$ of $2.0 \mathrm{ag}$. The colorimetric array and the CMUT both showed the largest affinity towards BMK in their respective responses due to the dyes which doubled as the functional coating on the CMUT.

\section{REFERENCES}

[1] I. J. Forbes and K. P. Kirkbride, "The Origin of Alkenes in Illicit Amphetamine: An Examination of the Illicit Synthesis of Phenyl-2Propanone," Journal of Forensic Sciences, vol. 37, no. 5, pp. 1311-1318, 1992.

[2] K. K. Park, H. J. Lee, G. G. Yaralioglu, A. S. Ergun, Ö. Oralkan, M. Kupnik, C. F. Quate, B. T. Khuri-Yakub, T. Braun, J.-P. Ramseyer, H. P. Lang, M. Hegner, C. Gerber, and J. K. Gimzewski, "Capacitive micromachined ultrasonic transducers for chemical detection in nitrogen," Applied Physics Letters, vol. 91, 2007.

[3] H. J. Lee, K. K. Park, M. Kupnik, Ö. Oralkan, and B. T. KhuriYakub, "Chemical Vapor Detection Using a Capacitive Micromachined Ultrasonic Transducer," Anal. Chem., vol. 83, pp. 9314-9320, 2011.

[4] K. K. Park, H. Lee, M. Kupnik, Ö. Oralkan, J.-P. Ramseyer, H. P. Lang, M. Hegner, C. Gerber, and B. T. Khuri-Yakub, "Capacitive micromachined ultrasonic transducer (CMUT) as a chemical sensor for DMMP detection," Sensors and Actuators B: Chemical, vol. 160, p. $11201127,2011$.

[5] D. Virzonis, G. Vanagas, A. Ramanaviciene, A. Makaraviciute, D. Barauskas, A. Ramanavicius, W. Wen, and R. Kodzius, "Resonant gravimetric immunosensing based on capacitive micromachined ultrasound transducers," Microchim Acta, vol. 181, p. 17491757, 2014.

[6] H. J. Lee, K. K. Park, M. Kupnik, and B. T. Khuri-Yakub, "Functionalization layers for $\mathrm{CO} 2$ sensing using capacitive micromachined ultrasonic transducers," Sensors and Actuators B: Chemical, vol. 174, p. $8793,2012$.

[7] D. Barauskas, D. Pelenis, D. Virzonis, J. P. Baltrus, and J. Baltrusaitis, "Greenhouse Gas Molecule CO2 Detection Using a Capacitive Micromachined Ultrasound Transducer," Anal. Chem., vol. 88, no. 13, pp. 6662-6665, 2016.

[8] Q. Stedman, K.-K. Park, and B. T. Khuri-Yakub, "Distinguishing Chemicals Using CMUT Chemical Sensor Array and Artificial Neural Networks," IEEE International Ultrasonics Symposium Proceedings, 2014.

[9] A. I. H. Chen, L. L. P. Wong, Z. Li, S. Na, and J. T. W. Yeow, "Practical CMUT Fabrication With a Nitride-to-Oxide-Based Wafer Bonding Process," Journal of Microelectromechanical Systems, vol. 26, no. 4, pp. 829-836, 2017.

[10] K. Midtbø, A. Rønnekleiv, and D. T. Wang, "Fabrication and Characterization of CMUTs realized by Wafer Bonding," IEEE Ultrasonics Symposium, pp. 934-937, 2006.

[11] M. Engholm, T. Pedersen, and E. V. Thomsen, "Modeling of plates with multiple anisotropic layers and residual stress," Sensors and Actuators A: Physical, vol. 240, pp. 70-79, 2016.

[12] S. Fanget, S. Hentz, P. Puget, J. Arcamone, M. Matheron, E. Colinet, P. Andreucci, L. Duraffourg, E. Myers, and M. Roukes, "Gas sensors based on gravimetric detection - A review," Sensors and Actuators B: Chemical, vol. 160, pp. $804-821,2011$. 